\title{
OPTIMAL PROPERTIES OF FRESH ULTRA-HIGH-PERFORMANCE CONCRETE FOR HOMOGENEOUS METALLIC FIBRE DISTRIBUTION
}

Ernests Ozolins $^{1}$, Juris Zavickis ${ }^{2}$, Arturs Lukasenoks ${ }^{1}$, Arturs Macanovskis ${ }^{3}$

${ }^{1}$ Betona petījumu centrs, Latvia; ${ }^{2}$ Dzelzsbetons MB, Latvia; ${ }^{3}$ Riga Technical University, Latvia

ernests.ozolins@bpcentrs.lv, juris.zavickis@mbbetons.lv, arturs.lukasenoks@ rtu.lv, arturs.macanovskis@rtu.lv

\begin{abstract}
As concrete is one of the most widely used construction materials on the planet, it is essential to adopt its properties for a wide range of applications. Its high compressive strength makes it the ideal material for compressive load-bearing structures, such as walls and columns. The low tensile strength and brittle behaviour are considered the biggest disadvantages that considerably limit the application of the material. However, this can be overcome, when additional reinforcement, such as metallic rebars or fibres with high tensile strength, is introduced into the concrete matrix. This allows for the prevention of brittle fractures when concrete is subjected to tensile stress. There are certain differences in the application technology between rebars and fibres. Metallic rebars are designed and placed in the mould according to calculated tensile loads, thus requiring special preparation of formwork before pouring in fresh concrete. Whereas fibres are evenly distributed directly in fresh concrete during the mixing process. If the efficiency of rebars is mainly dependent on initial calculations and their spatial placement, then the efficiency of fibres is greatly affected by their distribution factor in concrete. As the density of metallic fibres is approximately 3 times higher than that of concrete, the prevention of sedimentation of the metallic fibres during curing is considered a major challenge for the application of such fibres. In our work, we are focusing on obtaining a uniform distribution of high tensile strength metallic microfibers. Self-compacting high-performance concrete with an aggregate diameter of less than $1.25 \mathrm{~mm}$ was used as a matrix and high tensile strength metallic fibres with an aspect ratio of 40 were used as reinforcement. Different superplasticizer concentrations were used to modify the rheology of the mix until uniform fibre distribution was obtained, and sedimentation of fibres was prevented.
\end{abstract}

Keywords: UHPC, UHPFRC, fibre distribution, rheology.

\section{Introduction}

Recent advancements in concrete technology have allowed for a new generation of concrete products to be made - ultra-high-performance concrete (UHPC) [1]. It has high compressive strength, dense structure, self-levelling capability and low capillary porosity. In order to improve its brittle behaviour and to provide better post-cracking behaviour, steel fibres are added to the matrix, creating ultra-high-performance fibre reinforced concrete (UHPFRC) [2;3].

The tensile strength of the UHPC matrix reinforced with steel fibres will vary significantly depending on the number of fibres that have sedimented to the bottom of the sample. The top part of a sample will perform much worse in mechanical tests than the bottom part of the sample if sedimentation is severe [1]. This effect can negatively affect the longevity of a structure, thus, it is very important to ensure as homogeneous fibre distribution as possible.

Previous studies have shown that steel fibres are not uniformly distributed within UHPC due to but not limited to factors, such as the compacting process and rheology of the fresh concrete, as well as the geometry of the formwork [3-6]. For instance, an increased height of casting formwork can affect the fibre distribution negatively due to the increased kinetic energy the metallic fibres possess [7].

The sedimentation of fibres can also be attributed to the low yield stress of a particular concrete matrix. That is because when the shear stress that is applied, for example, by gravity or by pouring concrete into a formwork, it is higher than the yield stress of the particular mix, it flows [8; 9]. The same principle then applies to fibres that are within concrete. If the shear stress that the fibres are able to apply to the matrix is greater than the yield stress of the mix, the fibres will slowly sediment as long as the concrete is still in a fresh, fluid state. This can occur due to the fibre density being much higher than that of the concrete, the inertia of the fibres due to pouring, and the buoyancy not being able to compensate for the difference in density between the materials [7; 10]. A clear correlation between the reduction of the yield stress and an increase in the degree of steel fibre sedimentation has also been shown in previous studies $[1 ; 10]$.

Due to the self-levelling nature of the UHPC matrix, a relatively low yield stress of the mix is expected. Adjusting the amount of superplasticizer (SP) within the mix is a great tool to alter the yield 
stress of a certain concrete mix. Increasing the SP dosage will lead to a reduction in yield stress and a reduction in SP dosage will lead to an increase in the yield stress of the concrete mix [11]. It is also expected that the addition of lignosulfonate admixture will allow for more controllable rheology for the UHPC matrix. In addition, workability is also an important factor to consider, as poor workability of concrete will lead to increased porosity and entrapped air reducing the mechanical performance of UHPC [10].

By analysing the cross-sectional surfaces of samples, it has been proven that initially the increase in the yield stress improves the fibre distribution within the mix, however, it was also found that excessive reduction in the yield stress worsens the homogeneity of the fibre distribution $[7 ; 10]$. That is why a compromise between workability and sufficiently high yield stress for reduced fibre sedimentation has to be found for a certain UHPC matrix and fibre combination, which is the aim of this study.

\section{Materials and methods}

Materials used in the study.

- Aalborg white cement as the primary binder (Specific gravity of 3.15, mean particle diameter of $12.7 \mu \mathrm{m}$ and specific surface area of $1676 \mathrm{~m}^{2} \cdot \mathrm{kg}^{-1}$ ).

- Elkem micro silica 940U (Specific gravity - 2.2, mean particle diameter - $0.316 \mu \mathrm{m}$, a specific surface area greater than $\left.15 \mathrm{~m}^{2} \cdot \mathrm{g}^{-1}\right)$.

- Punkte test optimized mix of 4 quartz fractions from our previous study with a specific gravity of 2.612 and maximum grain size of $1.25 \mathrm{~mm}$ [12].

- Acrylic polymer-based SP with $35 \%$ solid content.

- Lignosulfonate admixture with a solid content of $20 \%$.

- Straight, round steel microfibres in length of $12.5 \mathrm{~mm}$ and diameter of $0.3 \mathrm{~mm}$ (density $\left.7850 \mathrm{~kg} \cdot \mathrm{m}^{-3}\right)$.

- Tap water.

The SP dosage was varied throughout the study to change the rheology of the UHPC mix. Lignosulfonate admixture was also added in various dosages to allow for better control of the rheology. The other parts of the mix design were kept the same to ensure consistency. Fixed UHPC mix design that was used in the study $-760 \mathrm{~kg} \cdot \mathrm{m}^{-3}$ of cement, $40 \mathrm{~kg} \cdot \mathrm{m}^{-3}$ of micro-silica (MS), $1313.9 \mathrm{~kg} \cdot \mathrm{m}^{-3} \mathrm{of}$ optimized quartz fraction and set water to binder ratio of 0.25 . The dosage of micro steel fibres was fixed at $2 \%$ of the volume of the mix. Six different plasticizer dosages and combinations were trialled as outlined in the table below.

Table 1

Plasticizer dosages used in this study

\begin{tabular}{|c|c|c|}
\hline Reference & SP dosage, \% wtob & Lignosulfonate dosage, \% wtob \\
\hline FT-1 & $1.10 \%$ & - \\
\hline FT-2 & $1.05 \%$ & - \\
\hline FT-3 & $1.03 \%$ & - \\
\hline FT-4 & $1.00 \%$ & $0.15 \%$ \\
\hline FT-5 & $1.00 \%$ & $0.30 \%$ \\
\hline FT-6 & $0.95 \%$ & $0.50 \%$ \\
\hline
\end{tabular}

For precise measurements scales (LW Measurements HRB series scales) with the accuracy of up to $0.1 \mathrm{~g}$ were used to weigh quartz, cement and MS. Scales with a precision of up to $0.01 \mathrm{~g}$ (SF-400C) were used to weigh water and SP for tests.

Zero-point nine litres of concrete were made for each batch of tests. Concrete was mixed in a HOBART Laboratory Mortar Mixer. All four sand fractions are put in the mixer first and mixed until a homogeneous mix is obtained. Then cement and MS are added to the mixer and it is further mixed for another 2 minutes. After that, a mixture of water and the required admixture dosage is poured into the mixer. After 5 minutes or once the mix has achieved a homogenous consistency, if it takes longer than 5 minutes, steel fibres are added to the mix. Concrete is then mixed further for 5 more minutes. 
A slump flow test was done in accordance with ASTM C230 standard. The time it takes for concrete to reach a slump of $20 \mathrm{~cm}$ in diameter, T20 time, as well as the maximum slump flow diameter, Dmax, were measured.

Samples for fibre sedimentation determination were made using prisms with dimensions 40x40x160 mm, concrete was poured in one go and no additional compaction was done. From each testing batch, 3 prisms were made. The prisms were then cut into 4 similarly sized parts. To determine the degree of sedimentation of fibres, the fibres present in the cross-section were counted within two regions - the top 3/8's and the bottom 3/8's of the cross-section of the sample surface, shown in Fig. 1. For each of the 4 cut parts of the prism, only one surface was used for the purpose of counting the fibres. This means that a sample size of 12 was used for each of the concrete mixes tested in this study. Error bars shown in Fig. 2 and Fig. 3 represent the overall variation in the obtained sedimentation coefficient and the data point represents the average obtained value of the sedimentation coefficient.

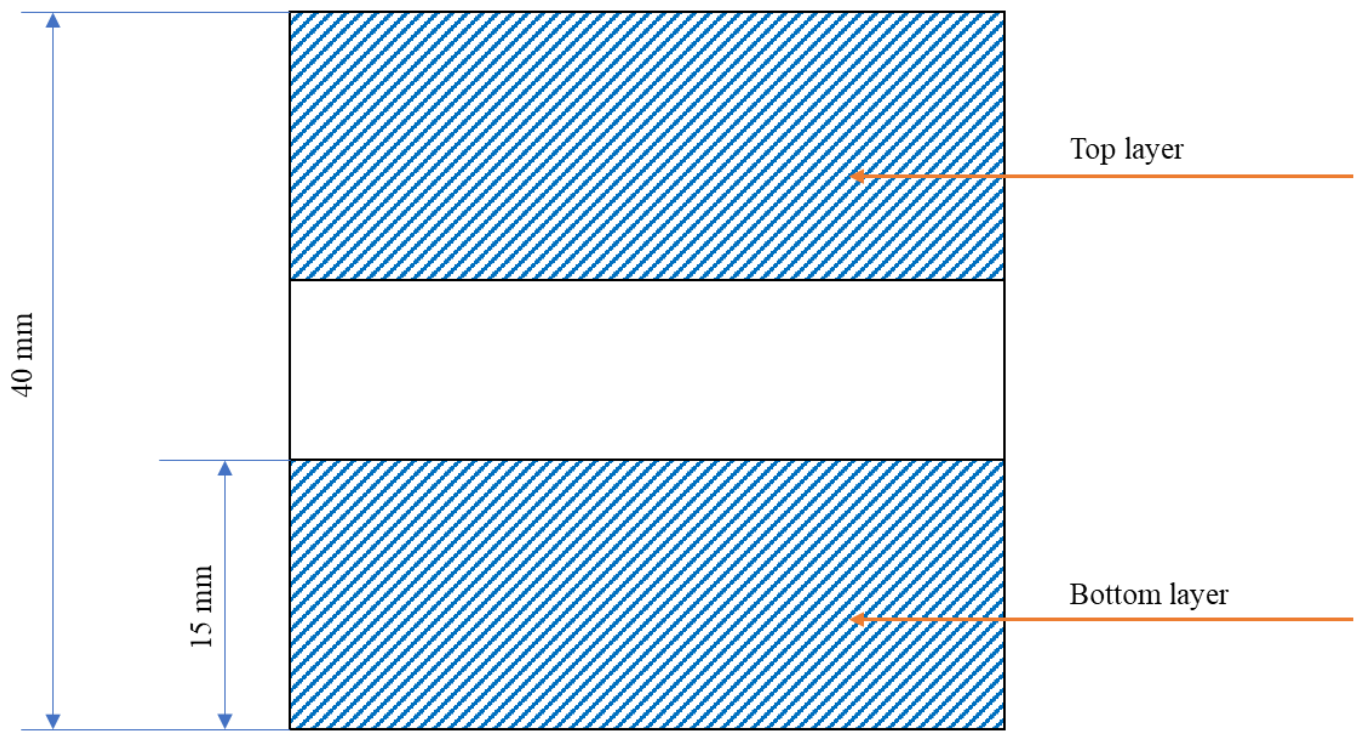

Fig. 1. Regions of prism cross-section within which fibre count has been compared

The sedimentation coefficient was calculated by dividing the number of fibres in the top layer of the sample surface with the number of fibres in the bottom layer of the sample surface. In these calculations the optimal value for the coefficient is 1 , which means that the top and bottom layers have the same number of fibres in them. A coefficient of less than 1 means that there are more fibres present in the bottom layer of the surface. A coefficient of more than 1 means that there are more fibres at the top layer of the surface than at the bottom layer.

\section{Results and discussion}

As it can be seen in Table 2, we obtained several different variations of the maximum slump flow varying from 25 to $32 \mathrm{~cm}$, as well as the relative viscosity of the concrete mix with the T20 time varying from 4 to 10 seconds. The results show that the use of lignosulfonate does allow for more precise rheology control and can be used in conjunction with SP. It means that the rheology of the mix will not significantly change for minute changes in the lignosulfonate dosage rate. However, once SP dosage was slightly altered, the rheology of the mix changed significantly as it is shown by mixes FT-2 and FT3 . The SP dosage was reduced by $0.02 \%$ by wtob, but the T20 time increased by 3 seconds and the maximum slump flow was reduced by $3 \mathrm{~cm}$.

When comparing the obtained fibre sedimentation coefficient to the maximum slump flow value, it can be seen that there is clearly a maximum slump flow value of a mix, at which there was no resistance to sedimentation of the fibres $-32 \mathrm{~cm}$. It can be seen in Fig. 2 that the sedimentation coefficient is reduced when maximum slump flow is increased. The results suggest that for the UHPC matrix mix that was used in this study the maximum slump flow value that can sustain low levels of fibre sedimentation is $28 \mathrm{~cm}$. This corresponds to mix FT-4. 
Obtained rheological parameters of the tested UHPC mixes

Table 2

\begin{tabular}{|c|c|c|}
\hline Reference & T20, $\mathbf{s}$ & Dmax, cm \\
\hline FT-1 & 4 & 32 \\
\hline FT-2 & 5 & 30 \\
\hline FT-3 & 8 & 27 \\
\hline FT-4 & 7 & 28 \\
\hline FT-5 & 10 & 25 \\
\hline FT-6 & 8 & 27 \\
\hline
\end{tabular}

The analysis of the obtained data led to the development of a mathematical model for the sedimentation coefficient dependency on the maximum slump flow of the UHPC mix. The obtained equation is presented in Fig. 2 and represented as the red dotted line in the graph. The $\mathrm{R}$ factor for the obtained model is 0.92 indicating the integrity of the obtained results.

By reducing the SP dosage, the relative yield value of concrete is increased. As the maximum slump flow value is greatly affected by the yield stress value of the mix, it can be assumed that reduction in the maximum slump flow is linked to a reduction in the yield stress. This will lead to minimised sedimentation of steel fibres. Other researchers also agree with this finding $[3 ; 10]$. This is because the concrete mix not only requires a higher force placed upon it to initiate the flow of itself, but it also resists the flow of material within it more. However, once the minimum required yield value to resist metallic fibre sedimentation has been achieved, a further increase will improve the sedimentation resistance properties of the mix with less efficiency, as is shown in Fig. 2.

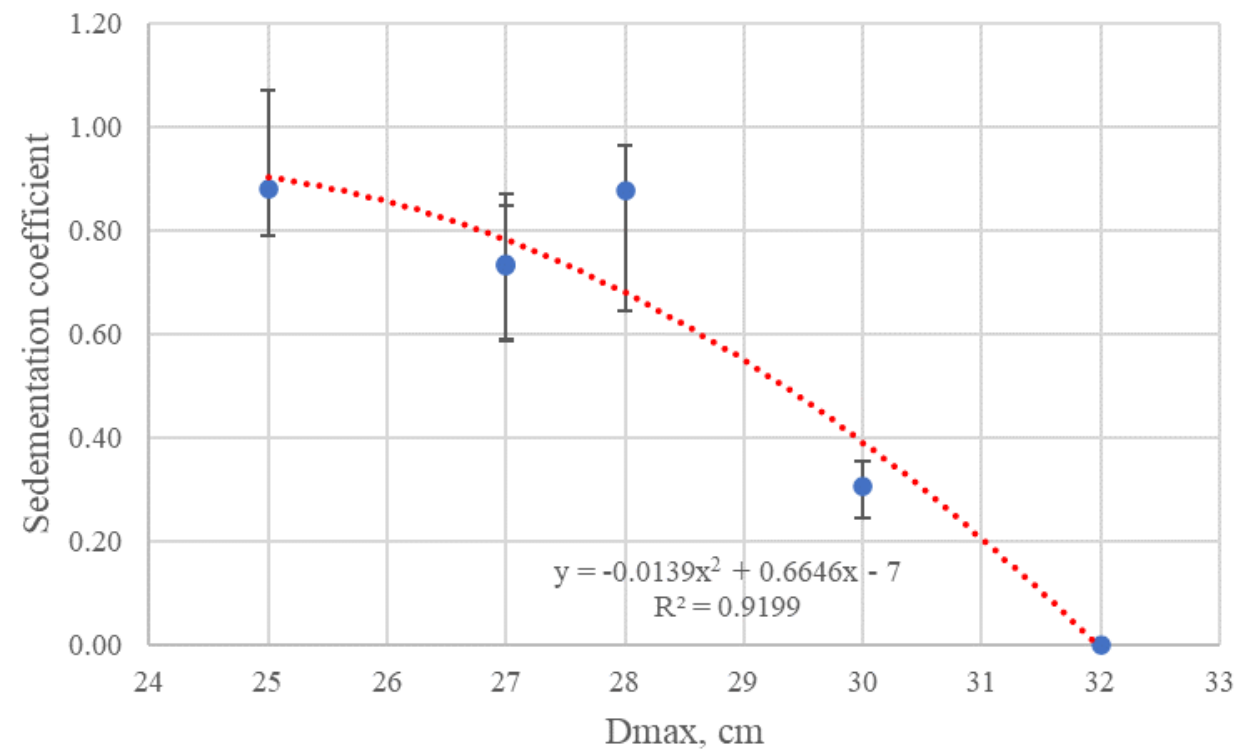

Fig. 2. Slump flow of UHPFRC mix vs fibre sedimentation coefficient

Relative viscosity measurements also show a great reliance for minimised sedimentation of fibres to the relative viscosity of the mix. As the resistance of the matrix to flow is increased, the downward flow of metallic fibres that are being pushed downwards by gravity and inertia does not change leading to reduced sedimentation. The biggest improvement in the sedimentation resistance can be seen, when the T20 time increases from 5 to 7 seconds, with an increase in the fibre sedimentation coefficient from 0.31 to 0.88 . Any further increase in the relative viscosity does not yield a significant improvement for the sedimentation coefficient.

Mathematical analysis of the obtained results led to the development of a mathematical model. The model predicts the sedimentation coefficients reliance on the relative viscosity of the mix, measured in seconds to reach $20 \mathrm{~cm}$ slump flow. The model is presented in Fig. 3 as the red dotted line and has a Rfactor value of 0.93 , indicating the soundness of the obtained results. 


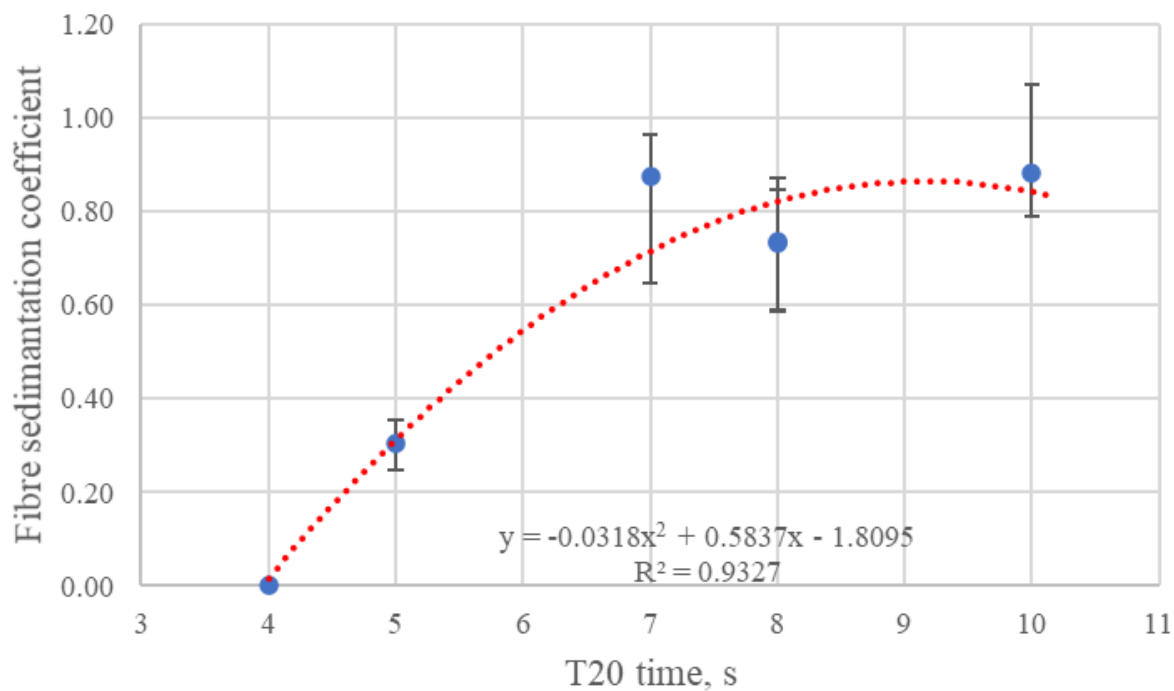

Fig. 3. T20 time (relative viscosity) vs fibre sedimentation coefficient

The obtained results indicate that there are limit values for the plastic viscosity and the yield stress values, above which metallic fibre sedimentation will be minimal. As the results show and other researchers agree, these values can be controlled effectively by adjusting the dosage of admixtures $[1 ; 3]$. This is because admixtures work by repelling cement particles from each other. The more admixture is added to the mix, the weaker is the initial bond between the cement particles and less water is trapped between them. This leads to reduced viscosity and a reduction in the shear force required for sedimentation to occur [1]. The opposite is true for the reduction of SP.

\title{
Conclusions
}

1. For the UHPC matrix mix that was tested in this study the minimum requirements for an acceptable level of metallic fibre, that were used in this study, sedimentation was found. The maximum slump flow of less than or equal to $28 \mathrm{~cm}$ and a T20 time of 7 seconds or more is required for optimal fibre distribution.

2. Based on the mathematical models, the tested steel fibre sedimentation coefficient can be predicted based on either the maximum slump flow of the matrix or the relative viscosity.

3. The use of lignosulfonate admixture allows for more precise control of UHPC rheology when used in conjunction with SP, meaning that minute changes in lignosulfonate dosage will not lead to great changes in the concrete rheology. However, minute changes in the SP dosage can lead to a significant change in the rheology of concrete.

4. Further research has to be done to show how the aspect ratio, as well as the shape of the metallic fibres can affect the minimum viscosity requirements for optimal fibre sedimentation characteristics.

\section{Acknowledgements}

In accordance with the contract No. 1.2.1.1/18/A/007 between "Competence centre of smart materials and technologies" Ltd. and the Central Finance and Contracting Agency, concluded on 23rd of April, 2019, the study is conducted by "Dzelzsbetons MB" Ltd. with support from the European Regional Development Fund (ERDF) within the framework of the project "Competence centre of smart materials and technologies".
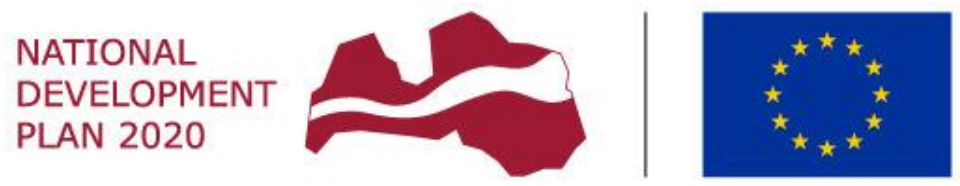

EUROPEAN UNION

European Regional Development Fund

\author{
IN VESTING IN YOUR FUTURE
}




\section{References}

[1] Wang R., Gao X., ZhangJ., Han G. Spatial distribution of steel fibers and air bubbles in UHPC cylinder determined by X-ray CT method. Construction and Building Materials, vol. 160, 2018, pp.39-47.

[2] Gowripalan N., Gilbert, R.I. Design guidelines for ductal prestressed concrete beams. Reference Artical, The University of NSW, 2000.

[3] Song Q., Yu R., Shui Z., Wang X., Rao S., Lin Z., Wang Z. Key parameters in optimizing fibres orientation and distribution for Ultra-High Performance Fibre Reinforced Concrete (UHPFRC). Construction and Building Materials, vol. 188, 2018, pp.17-27.

[4] Ferrara L., Meda A. Relationships between fibre distribution, workability and the mechanical properties of SFRC applied to precast roof elements. Materials and Structures, vol. 39(4), 2006, pp.411-420.

[5] Kim S.W., Kang S.T., Park J.J., Ryu G.S. March. Effect of filling method on fibre orientation and dispersion and mechanical properties of UHPC. In Proceedings of the 2nd International Symposium on Ultra High Performance Concrete, Kassel, Germany, 2008, pp. 185-192.

[6] Dils J., Boel V., De Schutter G. Influence of cement type and mixing pressure on air content, rheology and mechanical properties of UHPC. Construction and Building Materials, vol. 41, 2013, pp. 455-463.

[7] Larsen I., Thorstensen R. The influence of steel fibres on compressive and tensile strength of ultra high performance concrete: A review. Construction and Building Materials, vol. 256, 2020, p.119459.

[8] Faroug F., Szwabowski J., Wild S. Influence of superplasticizers on workability of concrete. Journal of materials in civil engineering, vol. 11(2), 1999, pp.151-157.

[9] Tattersall G.H., Banfill P.F.G. The Rheology of Fresh Concrete Pitman. Publishing, London, 1983.

[10] Wang R., Gao X., Huang H., Han G. Influence of rheological properties of cement mortar on steel fiber distribution in UHPC, 2021.

[11] Wallevik O.H., Wallevik J.E. Rheology as a tool in concrete science: The use of rheographs and workability boxes. Cement and concrete research, vol. 41(12), 2011, pp.1279-1288.

[12]Zavickis J., Lukasenoks A., Macanovskis A., Tupesis M. Optimization of packing of local coarse aggregates for use in UHPC (Ultra-High-Performance Concrete). 19th International Scientific Conference Engineering for Rural Development Proceedings, 2020. 